\title{
DENSITY, SOMA SIZE, AND REGIONAL DISTRIBUTION OF RABBIT RETINAL GANGLION CELLS ${ }^{1}$
}

\author{
CLYDE W. OYSTER, ${ }^{2}$ ELLEN S. TAKAHASHI, AND DAVID C. HURST* \\ Department of Physiological Optics, School of Optometry/The Medical Center, and ${ }^{*}$ Department of Biostatistics, University of Alabama in \\ Birmingham, Birmingham, Alabama 35294
}

\begin{abstract}
Cell soma area or diameter distributions are generally very skewed and present some unusual problems in characterization and description. In this study of ganglion cell soma size in rabbit retina, our conclusions are based on a statistical method which not only characterizes this particular neuronal population but which also may be of considerable value in other species and other parts of the nervous system.

To facilitate comparisons between retinas, we used ganglion cell density as the measure of retinal location. The rabbit retina has a horizontally extended area centralis, the visual streak, which we show to have a uniformly high peak cell density along most of its length. Cell density maps were used to estimate the total number of ganglion cells in the retina; the mean for three retinas was about 406,000 cells, which corresponds well to an earlier count of optic nerve axons $(394,000 \pm 20,000$; Vaney, D. I., and A. Hughes (1976) J. Comp. Neurol. 170: 241-252).

Contrary to other reports, we could not find any large differences in ganglion cell size distributions between the inferior peripheral retina and the visual streak nor could we confirm the report of a large cell area temporalis (Provis, J. M. (1979) J. Comp. Neurol. 185: 121-138). Cell size distributions in the superior and inferior retina were very different, however, and, within the inferior retina, there was a small but systematic change in cell size between the periphery and the visual streak. In general, small and medium size cells were present in nearly constant proportions throughout the inferior retina, while the large ganglion cells showed a small decrease in proportion from the periphery to the visual streak; the decline in large cells was a linear function of cell density. In terms of ganglion cell soma size, there was no sharp distinction between the visual streak and the peripheral retina.
\end{abstract}

Soma sizes in neuronal populations have been investigated throughout the central nervous system. Among other things, soma size has been used to delimit specific nuclei or nuclear subdivisions, to characterize normal growth and development, and to demonstrate the effects of deafferentation or alteration of sensory input. In the retina, the possibility of a relationship between soma size and physiological or morphological cell classes has prompted a number of studies on ganglion cell soma size and variation with retinal location.

\footnotetext{
${ }^{1}$ We are particularly grateful to Ms. Laura Engstrand for her painstaking work on this project. We also thank Ms. Myong-Suk Lee for assistance with ganglion cell counts and Dr. Terry L. Hickey for his thoughtful critique of this paper. The research was supported in part by United States Public Health Service Grant EY 02207 and CORE Grant EY 03039. At the time the work was performed, C. W. Oyster held a Research Career Development Award from the National Eye Institute.

${ }^{2}$ To whom correspondence should be addressed.
}

A problem common to quantitative studies of cell size is that of dealing with size distributions which are generally unimodal, sometimes multimodal, and often very skewed. Normal, or Gaussian, distributions are the exceptions. As a result, cell size distributions do not lend themselves to the use of familiar statistics, such as means and standard deviations, thus creating difficulty in characterizing the distributions and evaluating any changes which occur along a particular experimental variable. In this study of rabbit retinal ganglion cell size, we will apply a method which circumvents these difficulties and, in consequence, should be useful in studies of other neuronal populations.

Ganglion cell size in rabbit retina is of interest principally for two reasons: first, the rabbit retina contains a variety of physiologically classified ganglion cells (Barlow et al., 1964; Levick, 1967; Caldwell and Daw, 1978), some or all of which may be associated with somata of specific size ranges. There is already evidence that one cell class, the on-type direction-selective cells, have somata which 
are among the largest in the ganglion cell population (Oyster et al., 1980). Second, the rabbit retina has a large, horizontally extended area centralis, the visual streak (Davis, 1929). The sheer size of this region facilitates physiological and anatomical studies concerned with the differences between the central and peripheral retina.

There have been three major anatomical studies of rabbit ganglion cells in which soma sizes have been measured (Hughes, 1971; Provis, 1979; Vaney, 1980). Although the initial study by Hughes was later shown to include an appreciable number of cells other than ganglion cells (Vaney and Hughes, 1976; Vaney, 1980), the original description of ganglion cell soma size variation with retinal location has remained basically intact. Peripheral retina is thought to contain mostly large and medium size cells, while the visual streak is dominated by small ganglion cells (Hughes, 1971; Vaney, 1980). Provis (1979) also has reported that a subgroup of very large ganglion cells have their maximum density near the temporal end of the visual streak, thereby raising the possibility of some functional specialization in this region.

It is somewhat surprising, therefore, to note the soma size distributions reported by Oyster et al. (1980) in their study of ganglion cells labeled by horseradish peroxidase injections into the rabbit's medial terminal nucleus. The size distributions for unlabeled cells in the periphery and visual streak were different, but the differences were not large enough to be consistent with major systematic changes in cell size between the peripheral and central retina. It was largely this result which prompted us to reexamine ganglion cell soma size variation with retinal location.

In so doing, we needed to establish some measure of retinal location which would be consistent between retinas having different absolute dimensions and would not be dependent on a priori assumptions about symmetry. We chose ganglion cell density as our distance metric and therefore did cell counts as well as cell area measurements. Because of the significant variation in peak cell density between individual retinas shown by Provis (1979), we also felt it necessary to use several retinas in this study. Finally, for reasons considered at the outset of this discussion, the form of the cell size histograms presented some interesting and generally unaddressed problems in statistical evaluation. Our statistical method is fairly simple, yet it permitted us to characterize and describe the variation of ganglion cell soma size concisely throughout the rabbit retina. The method has sufficient flexibility to be widely applicable to description of cell size in other species and structures.

\section{Materials and Methods}

Histological procedures. The eyes used in this study were removed from deeply anesthetized New Zealand red rabbits which were killed by an overdose of $1 \%$ Surital (thiamylal sodium).

Each eyeball was placed in Ringer's solution and gently massaged to loosen the retina from the pigment epithelium, and the vitreous chamber was injected with $40 \%$ formaldehyde. The anterior segment, including the lens, was removed by cutting around the globe about 2 to 3 $\mathrm{mm}$ behind the limbus. By grasping the vitreous with forceps in the region where streaks of pigment from the ciliary body could be seen (i.e., near the vitreous base), the vitreous often could be removed as a whole.

Four scissor cuts were made in the eyecup so that the retina, when removed, could be flattened in the shape of a Maltese cross. The retina was teased away from the pigment epithelium with a soft brush, cut loose at the optic nerve head, and floated, vitreal surface up, onto a gelatinized slide. Excess fluid was blotted from the slide which then was placed in formalin vapor for about $1 \mathrm{hr}$.

After the retina was dry and affixed to the slide, it was washed in distilled water and then stained with either Richardson's stain (retina 105R) or cresyl violet (retinas $105 \mathrm{~L}$ and $103 \mathrm{R}$ ). The stained retina was washed, dehydrated in alcohol, cleared in terpineol, and covered with Permount and a coverslip.

Ganglion cell counts. Our microscope was equipped with $\mathrm{a} \times 63$ oil immersion objective and $\times 1.6$ intermediate magnification. The resulting overall magnification using the camera lucida was $\times 1000$ with a field of view of $0.024 \mathrm{~mm}^{2}$. The diameter of this field $(175.4 \mu \mathrm{m})$ corresponds to about $1^{\circ}$ of visual angle for the rabbit eye.

Ganglion cell counts were made at the intersections of a $0.5-\mathrm{mm}$ grid superimposed on the retina. At each step, all ganglion cells in the field were counted. Cells partially in the field were counted only if they intersected the upper border. The number of ganglion cells at a given location divided by the area of the count field gave the cell density. These values were indicated on a drawing of the retina magnified about 16 times by a microprojector and isodensity contours were plotted on this enlarged retinal density map.

In making the cell counts, a distinction was made between small ganglion cells and glia. This problem has been discussed in some detail by Stone (1978) and Hughes (1975) for ganglion cell counts in cat retina. Glia were distinguished by their location (they were often in the nerve fiber layer), differences in staining, and their smooth, generally oval contours. Cells classed as small ganglion cells looked more like irregular polygons.

Examples of cells omitted from our ganglion cell samples are shown in Figure 1. The uppermost photograph (Fig. $1 A$ ) is from the visual streak; with the exception of the small cells indicated by arrows, all of these somata would be designated as ganglion cells. In Figure $1, B$ and $C$ are of another group of cells photographed at higher magnification with the ganglion cells in focus in Figure $1 B$ and with a plane of focus slightly deeper in the retina (Fig. 1C). The small cell out of focus in $B$ (arrow) but more sharply focused in $C$ has a very smooth, almost circular contour and would not be classed as a ganglion cell.

We did not attempt to differentiate among the various types of cells which were excluded from our samples. It is likely that a substantial portion of the cells that we called "glia" and therefore omitted from the sample were "coronate cells" as described by Vaney (1980). We will consider this possibility in more detail later.

Ganglion cell area measurements. At 1-mm intervals, outline drawings were made with a camera lucida of all ganglion cell bodics in the microscope field. The areas enclosed by these outlines were measured using a cali- 

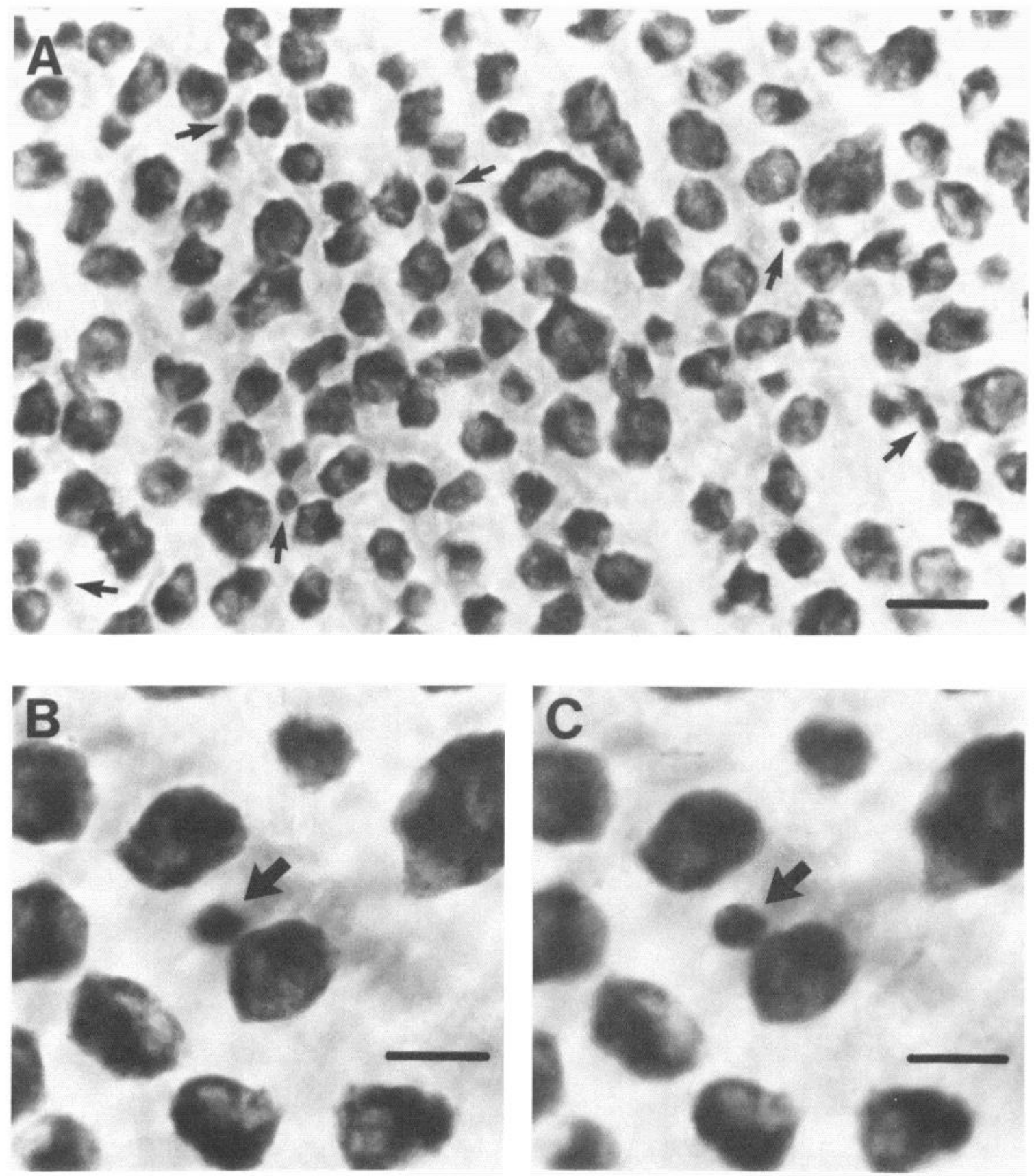

Figure 1. Photomicrographs of cells in the ganglion cell layer. The dimension scales are $20 \mu \mathrm{m}$ in $A$ and $10 \mu \mathrm{m}$ in $B$ and $C$. Cells to be excluded from the ganglion cell sample are indicated by arrows. In $A$, photographed in the visual streak, the cells not classed as ganglion cells are small and have noticeably smoother contours than their neighbors. Another small cell is slightly out of focus in $B$ (arrow) but is shown more clearly in $C$ when the plane of focus is slightly deeper in the retina. It also would be eliminated from the sample.

brated Numonics graphics calculator. Since the $x-y$ coordinates were recorded for each field of cells drawn, it was possible to relate cell size to retinal location.

There was an inherent variability in the measurement of cell area. Based on repeated measurements of different cell outlines, the standard deviation ranged from 3.21 to $8.06 \mu \mathrm{m}^{2}$. This is a conservative estimate of the error, however, and we made additional drawings of a single field of cells in which the field was rotated randomly about a fixed center between each drawing. Measure- ments of each identified cell in all drawings permitted an estimate of the combined drawing and measurement errors. The standard deviation for measurements on 91 cells was between 3.87 and $16.07 \mu \mathrm{m}^{2}$ and showed a slight increase with mean cell size. This error is still quite small and acceptable.

For any given cell, the outline drawing was made with the cell borders in good focus, which was usually the condition which gave a maximum cross-sectional area.

Data analysis. The basic form of the cell area data is 
a histogram showing the relative frequency of occurrence as a function of cell area. Frequencies were computed from the number of cells in successive increments of area (usually $10 \mu \mathrm{m}^{2}$ ) divided by the total number of cells in the sample $(N)$. That is, relative frequency $=n_{i} / N$. It is useful, however, to transform the cell size histogram to a cumulative frequency distribution by adding the relative frequencies in order. Thus, cumulative frequency $=(1)$ N) $\Sigma n_{i}$. Each data point now represents the fraction of cells in the sample having that area and smaller.

There are several advantages in using cumulative frequency distributions. These distributions lend themselves to quantitative statements, the summation by which they are generated tends to reduce the sampling noise inherent in the original histograms, and finally, there are statistical methods available by which the distributions may be compared. The Kolmogorov-Smirnov test is one example, but these tests are sensitive to a variety of features, such as skew, dispersion, and central tendency (e.g., Siegel, 1956), and can state only whether two distributions are different. Although this may be useful information, the result does not indicate the nature of the difference between distributions and is not readily applicable when more than two distributions must be compared. It is for these reasons that we took an additional step in the analysis.

We choose to model the cumulative frequency distribution by generating analytical curves to fit the cumulative frequency data. For this purpose, we used a family of flexible and relatively simple curves called Weibull functions (Johnson and Kotz, 1970). These functions have the form

$$
F(A)=1-\exp \left[-\{(\ln A-\ln \gamma) / \alpha\}^{\beta}\right]
$$

Where $A$ is the cell area and $\alpha, \beta$, and $\gamma$ are variable parameters of the distribution. The parameter $\gamma$ is a shift parameter which is approximately the size of the smallest cell area observed; we assigned $\gamma$ a constant value and then used a nonlinear curve-fitting routine (Marquardt, 1963) to estimate the values of $\hat{\alpha}$ (a scaling parameter) and $\hat{\beta}$ (a shape parameter) which produced the best fit curve for each set of cumulative frequency data. ${ }^{3}$ The probability density function which corresponds to the original cell size histogram is obtained by differentiating the Weibull cumulative distribution function.

Although the use of Weibull functions in the analysis may seem an unnecessary complication, there are significant benefits. For example, the curve-fitting procedure represents an additional smoothing operation, eliminating the inevitable sampling noise. In addition, calculations of quantitative values, such as medians or other percentiles, become extremely simple. Most important of all, however, is the ability to characterize fully a distribution by three numbers (i.e., by the parameters of the distribution). Because of this feature, one can not only demonstrate differences between cell size distributions but, as we will show, the nature of the differences can be specified.

\footnotetext{
${ }^{3}$ As an alternative to the nonlinear curve fitting, we have devised a simple graphical method for parameter estimation which requires only a hand calculator. Details are available on request.
}

\section{Results}

Ganglion cell density. The appearance of ganglion cells in a flat-mounted rabbit retina is illustrated by drawings from microscope fields from different retinal regions (Fig. 2). The areas selected encompass most of the range of cell density for this particular retina and were located on a line perpendicular to the visual streak.

Cell density was never very high; even in the uppermost field, from a location near the center of the visual streak, there is considerable space between adjacent cells. This field was superior to the highest density point in the streak and the next field $\left(2,814\right.$ cells $\left./ \mathrm{mm}^{2}\right)$ was just inferior to the peak. Cell density changes rapidly in this part of the retina, but successive fields show the reduced rate of change occurring in peripheral retina.

Note that all of the fields in Figure 2 show some large cells. They are more obvious in the lower density fields, but several are clearly present at the highest density as well. Similarly, very small and intermediate size ganglion cells can be observed in all fields. The impression is that some ganglion cells of all sizes can be found at any retinal locus, a point with which we will deal quantitatively in a later section.

Our ganglion cell counts are shown in their most complete form in Figure 3. Two of these perspective plots are included for each retina. The first, to the left, views each retina from its inferior-nasal aspect, while the second, to the right, shows the retina from the superior-nasal direction.

In all three retinas, the peak cell density appears as a serrated ridge extending along the center of the visual streak. Inferiorly, cell density falls quite rapidly down to 1,500 to 1,000 cells $/ \mathrm{mm}^{2}$, after which, density falls much more slowly out to the retinal periphery. A similar situation holds on the superior aspect of the visual streak except that the superior retina contains a region of zero density extending laterally from the optic nerve head. This region lies under the myelinated fiber band; although ganglion cell density is not strictly zero here, it is very low (e.g., Davis, 1929) and the myelination prevents adequate staining of the few cells present.

The peak cell densities in the three retinas are somewhat different and some local maxima can be seen; a local peak in the temporal retina of retina $105 \mathrm{~L}$ is particularly obvious. These retinas show considerably less individual variation than reported in earlier work (Provis, 1979), however, and the results are consistent with the notion that a line of high cell density, uniform to within about $\pm 10 \%$, extends along the center of the visual streak.

Variation in cell density along the center of the visual streak is most probably the result of the placement of the sampling grid. Density changes rapidly here and since the streak also is traversed by bundles of axons, shifts of the count grid by a few hundred micrometers could affect the calculated densities by 500 to 1,000 cells $/ \mathrm{mm}^{2}$. If any local region of particularly high cell density exists, it is smaller than $0.5 \mathrm{~mm}$ in extent (the size of our count grid) and has escaped detection in all three retinas.

The spatial relationships of the major isodensity contours to one another and to the optic nerve head are shown in Figure 4. As Hughes (1971) has reported, the center of the visual streak is approximately $3 \mathrm{~mm}$ below 


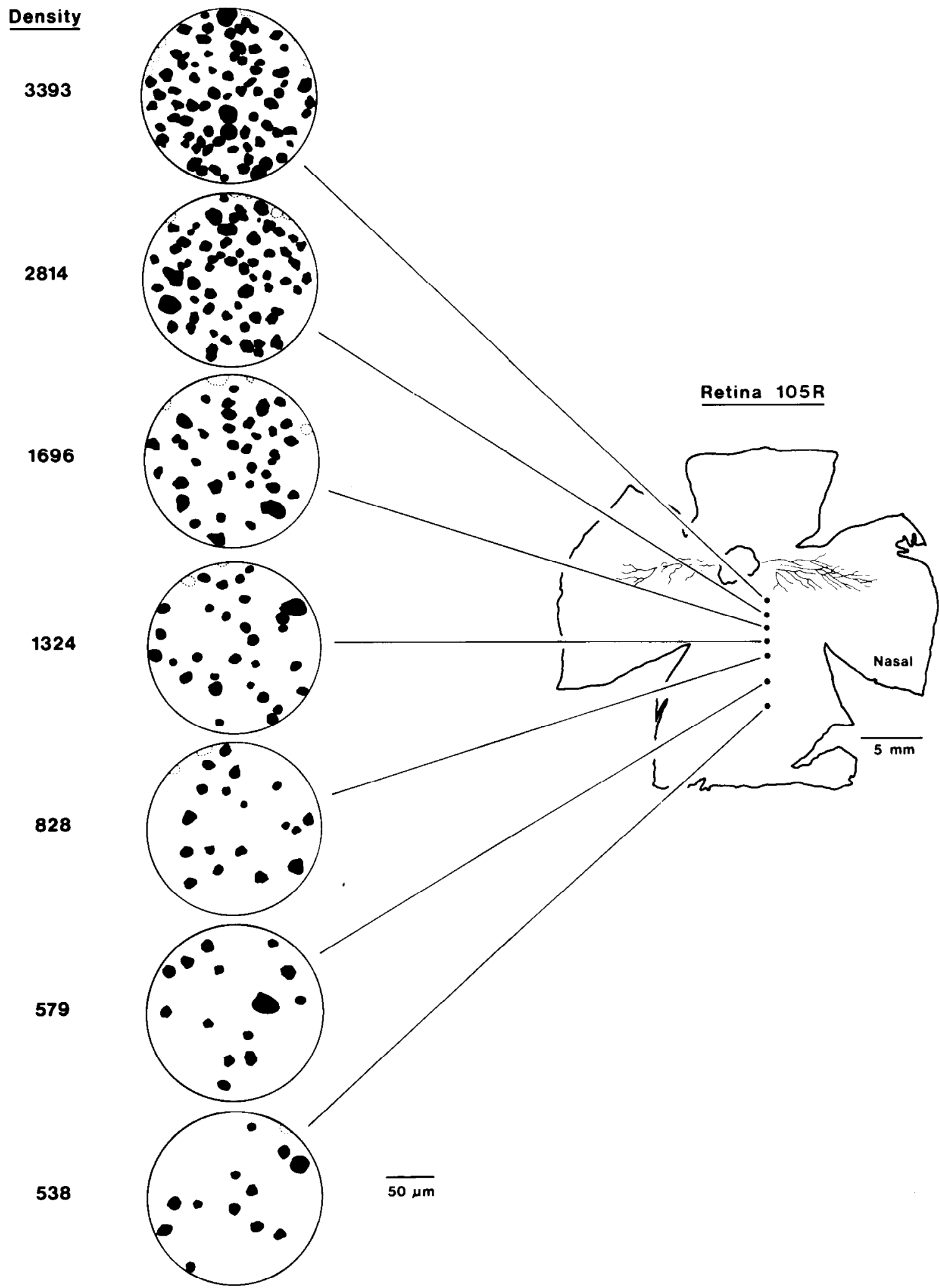

Figure 2. Microscopic views of ganglion cells at different retinal locations. Ganglion cell somata as seen and drawn through a camera lucida are illustrated for seven retinal locations along a line perpendicular to the visual streak. The upper five fields were separated by $1 \mathrm{~mm}$ on the retina, while the lower three were separated by $2 \mathrm{~mm}$. Cell densities, in cells per mm ${ }^{2}$, were obtained by dividing the number of cells (including those partially within the field, drawn with dotted outlines) by the area of the field of view $\left(0.024 \mathrm{~mm}^{2}\right)$. Cells classed as something other than ganglion cells were not drawn and none are included here.

the center of the nerve head. The entire visual streak, as defined by the 2,000 cells $/ \mathrm{mm}^{2}$ isodensity contour is, on average, about $26 \mathrm{~mm}$ long and $2 \mathrm{~mm}$ wide. In visual space, these dimensions correspond to $150^{\circ}$ in length and $11.6^{\circ}$ in vertical extent, assuming a posterior nodal distance of $9.9 \mathrm{~mm}$ (Hughes, 1972).

Ganglion cell soma size. Rabbit retinal ganglion cells are not unusually large. The largest cell measured had 


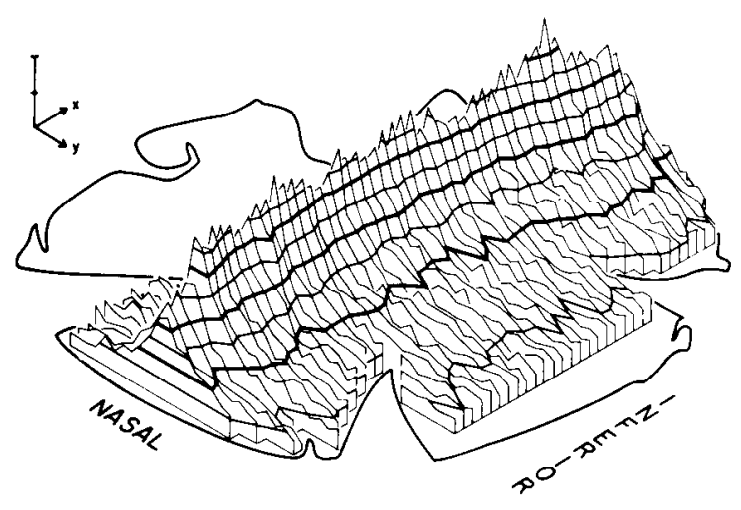

$105 L$
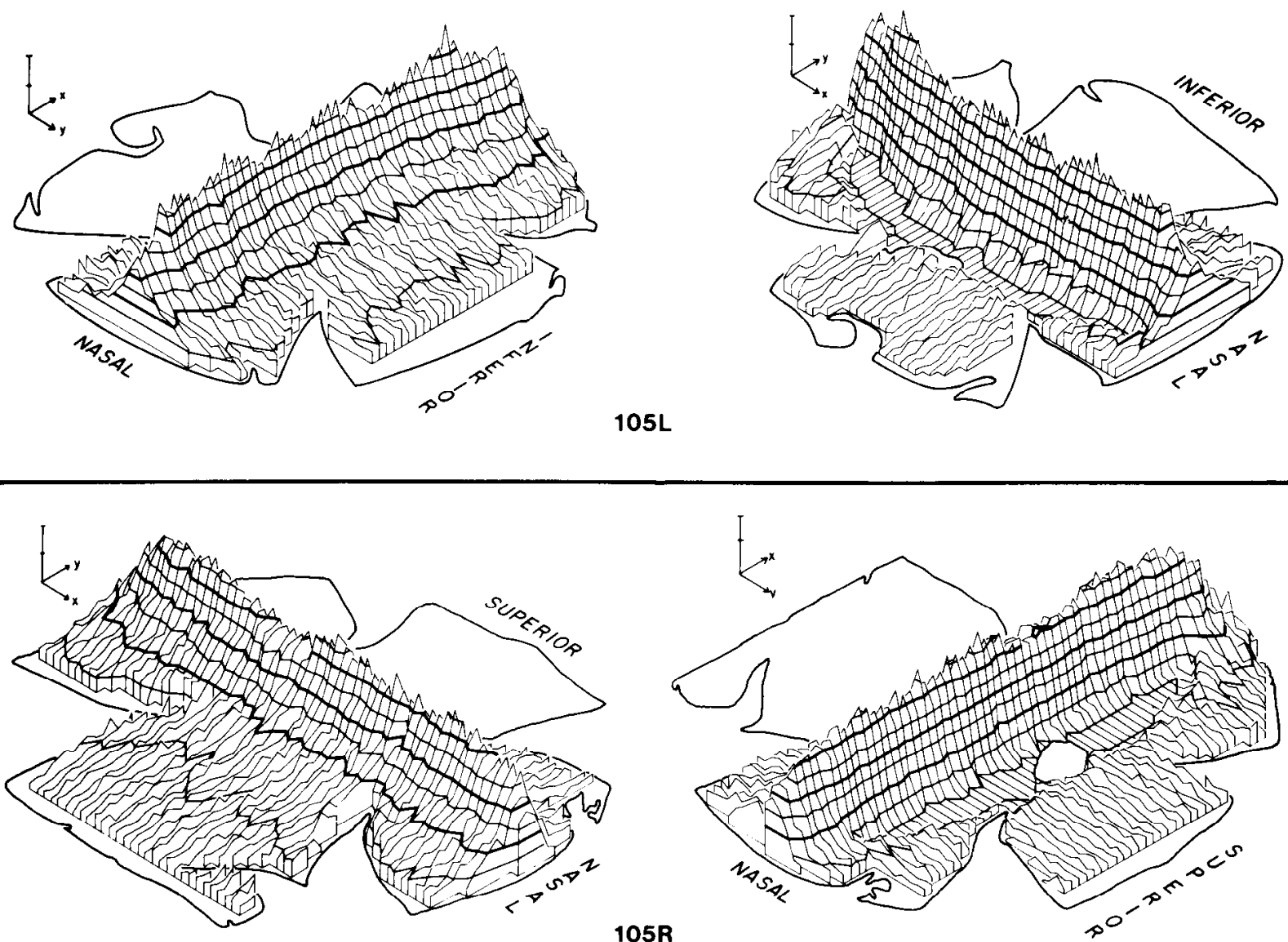

105R

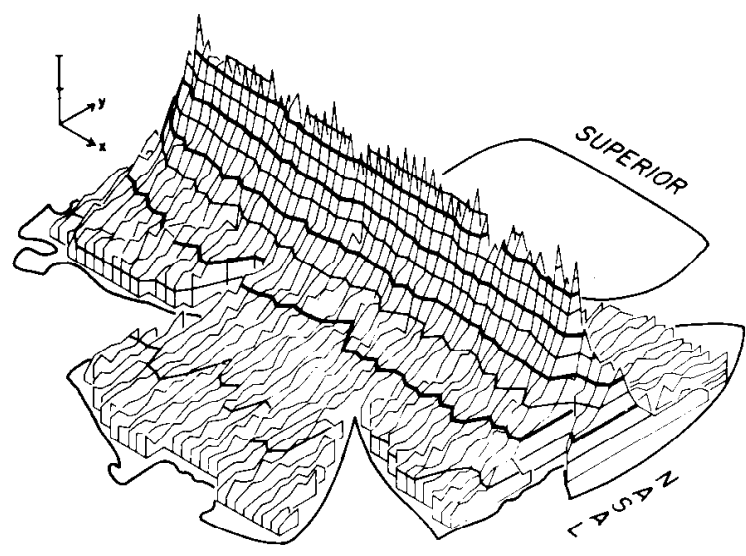

$103 R$

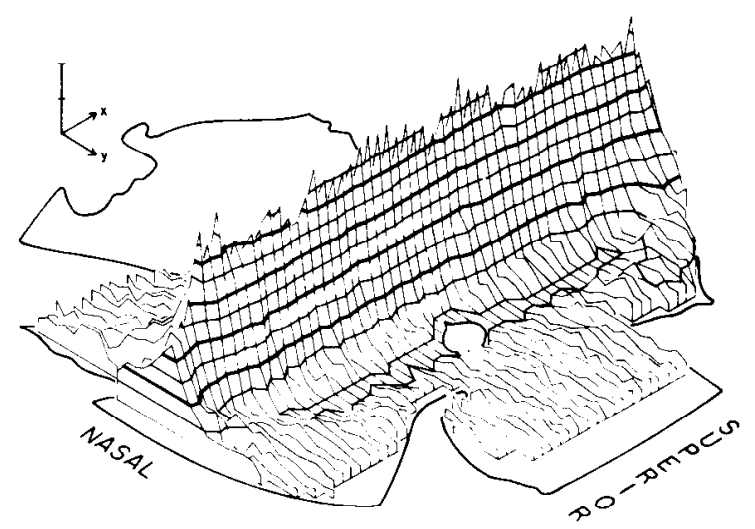

Figure 3. Ganglion cell density as a function of retinal location. Ganglion cells were counted and densities were computed at 0.5-mm intervals across the retina. For the three retinas shown here, densily has been plotted as the $z$ axis in a three-dimensional coordinate system. Isodensity contours have been plotted at 500 cells $/ \mathrm{mm}^{2}$ density increments, with the bolder contours at 1,000 cells $/ \mathrm{mm}^{2}$ intervals. Cell density is quite uniform along the visual streak which extends almost completely across the retina.

an area of $712 \mu \mathrm{m}^{2}$, corresponding to a mean diameter of about $30 \mu \mathrm{m}$. Only a small fraction of the total had areas larger than $300 \mu \mathrm{m}^{2}$ (20 $\mu \mathrm{m}$ diameter). The smallest cells were about $25 \mu \mathrm{m}^{2}$ in area or $6 \mu \mathrm{m}$ in diameter. This cell size range is similar to other results on rabbit retina (Bech, 1957; Hughes, 1971; Provis, 1979; Vaney, 1980) and in a variety of other species (cat: Hughes, 1975; Wässle et al., 1975; hamster: Tiao and Blakemore, 1976; 

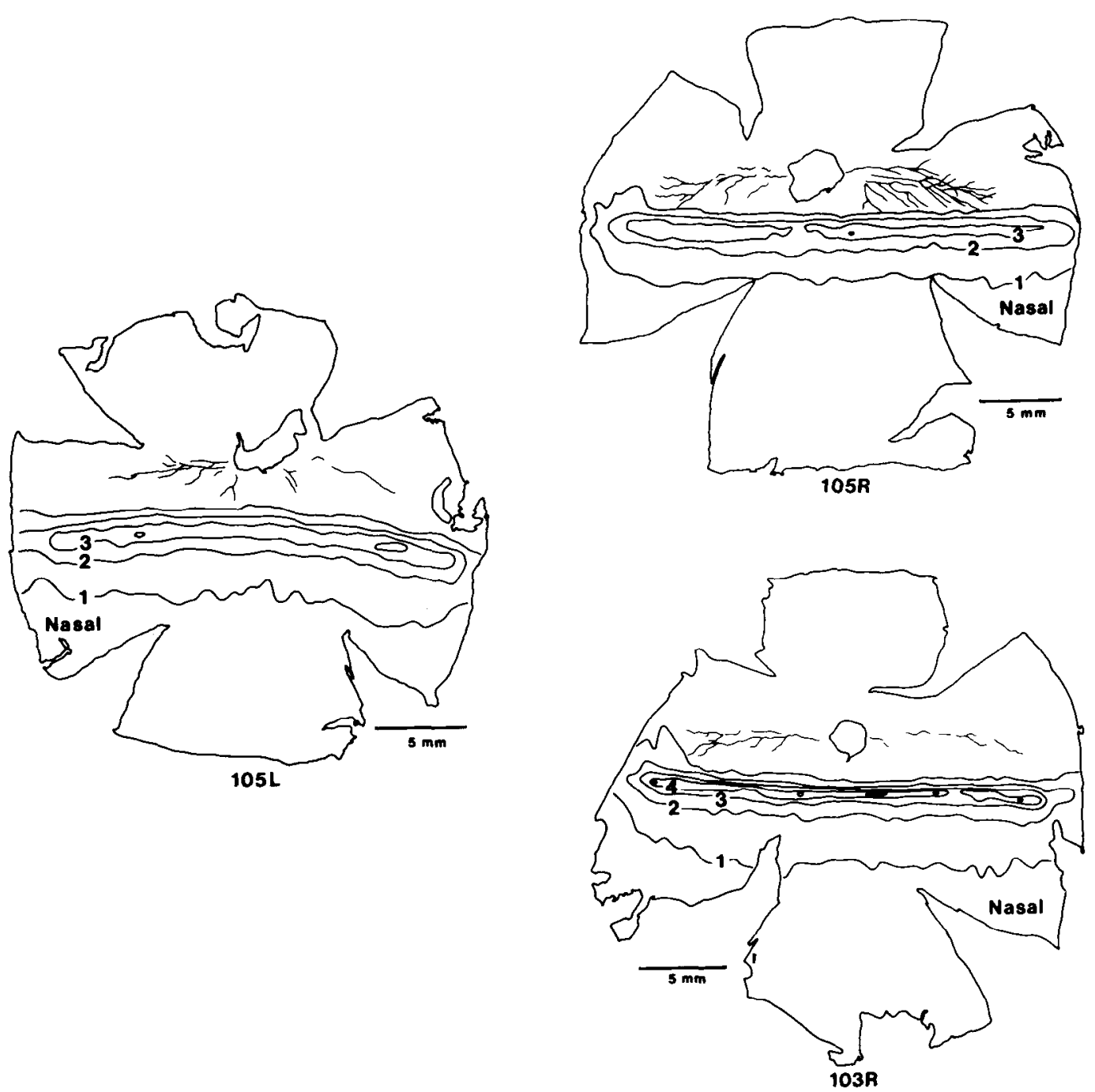

Figure 4. Ganglion cell isodensity contour maps. The isodensity contours at 1,000 cells $/ \mathrm{mm}^{2}$ intervals shown as bold lines in Figure 3 are reproduced here on plane views of the three retinas. The numbers on the isodensity contours, when multiplied by 1,000 , give the cell density. The visual streak, bounded by the 2,000 cells $/ \mathrm{mm}^{2}$ contour line, is about $26 \mathrm{~mm}$ long and 2 to $2.5 \mathrm{~mm}$ wide. The center of the visual streak is approximately $3 \mathrm{~mm}$ below the nerve head, shown by the irregularly shaped hole in the superior retina.

rat: Fukuda, 1977; opossum: Hokoc and Oswaldo-Cruz, 1979; possum: Freeman and Tancred, 1978; cow: Hebel and Hollander, 1979).

To show the variation of ganglion cell size with retinal eccentricity, we have used cell density as the measure of retinal location. The density regions were those defined by the isodensity contours in Figure 3 and all cells within each region were combined. For each density region, we generated a cell size histogram showing the relative frequency of occurrence as a function of cell area. These histograms are shown in Figure 5 for both retinas in which cell size measurements were made.

One obvious characteristic of the histograms is that they are unimodal. Although some histograms seem to have secondary maxima, this appearance is produced by unusually high or low relative frequencies in just one or two areal increments. This is sampling noise, and it cannot be regarded as significant.
A second general impression is the similarity of the histograms, particularly those from the inferior retina. Their maximum relative frequencies are between 0.1 and 0.12 and occur at cell areas between 75 and $100 \mu \mathrm{m}^{2}$. The most obvious trend in the data is the decrease in cell size range from the inferior periphery to the visual streak; there appear to be more large cells in the peripheral retina. It is also clear that there is no abrupt change in cell size distributions between the inferior periphery and visual streak. A more pronounced difference can be seen when comparing the histograms from the superior retina to their inferior retinal counterparts and it is for this reason that they will be treated separately. In all cases, the smooth curves plotted through the histograms form a basis for description. The curves have been derived from the data plotted as cumulative frequency distributions, however, and these are shown in Figure 6.

With the data in this form, the more extensive repre- 

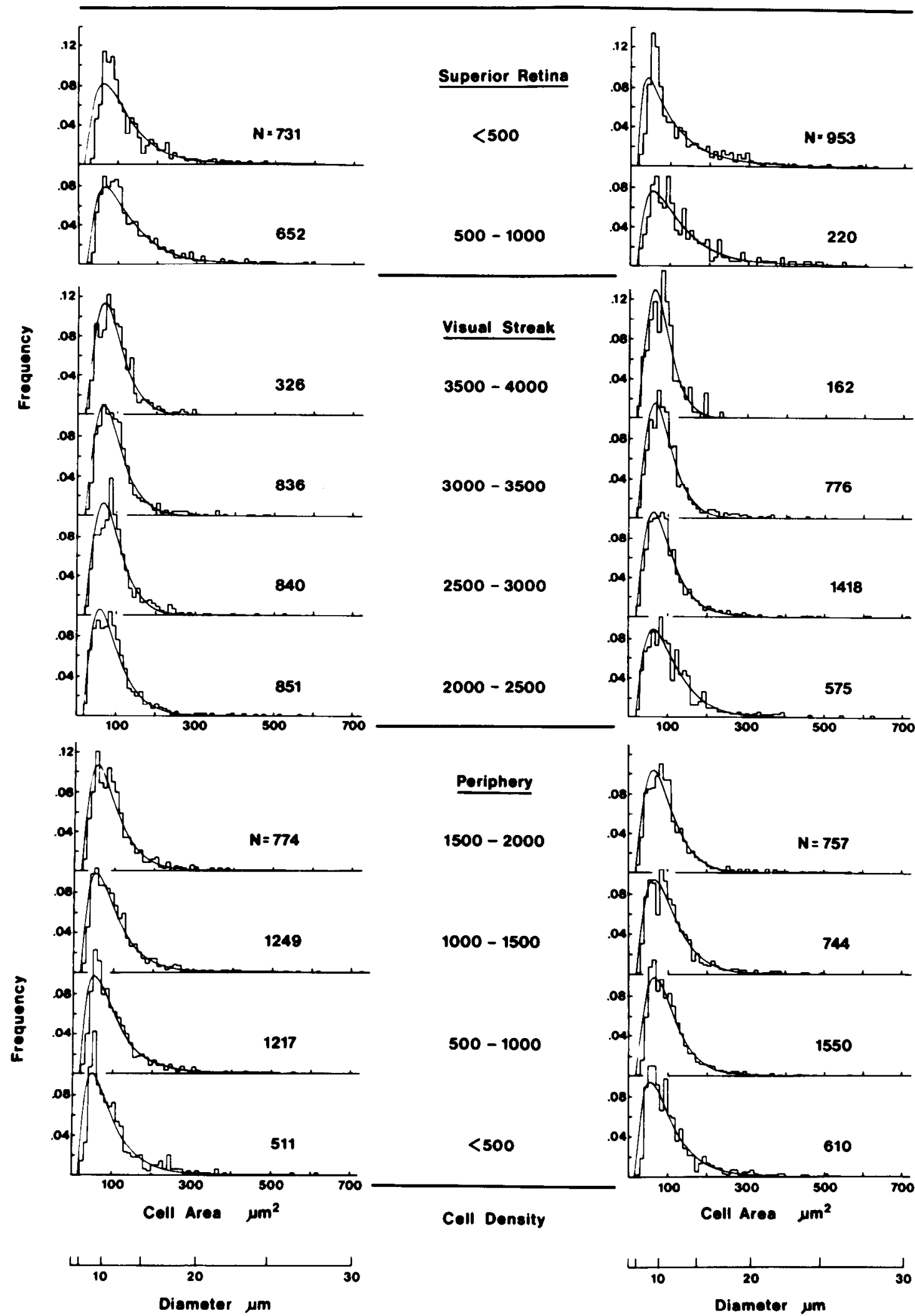

Visual Streak

$3500-4000$

$3000-3500$

$2500-3000$

$2000-2500$
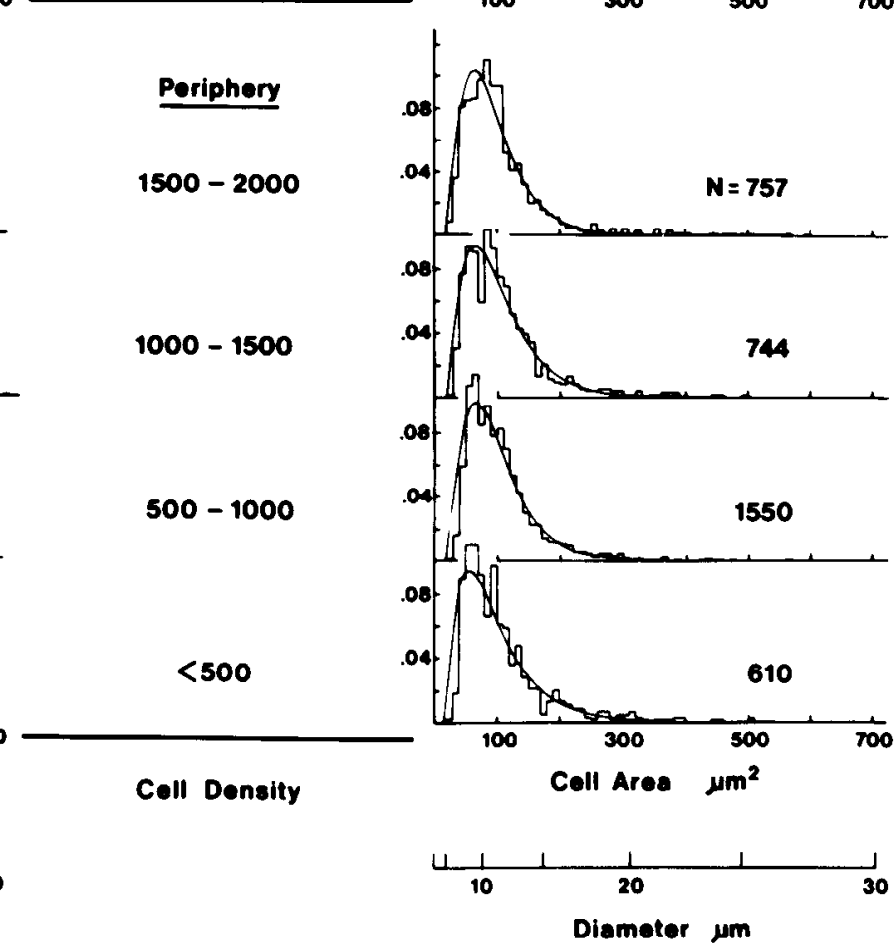

Figure 5. Cell size histograms as a function of cell density. The histograms were generated for each of the retinal regions bounded by the isodensity contours in Figure 3. $N$ refers to the number of cells in each sample. The cell size histograms were generated by dividing the range of areas into $10-\mu \mathrm{m}^{2}$ areal increments, counting the number of cells whose areas fell in each of these divisions, and dividing by the total number of cells in the sample. This relative frequency or probability of occurrence is the ordinate for the histograms. The curves fit through each histogram are Weibull probability density functions which are discussed in the text. Although cell densities in the superior and far peripheral inferior retina are comparable, the cell size histograms are clearly different. The superior retina contains more large cells. Within the inferior retina, the histograms exhibit a small change from the periphery to the visual streak; the streak histograms have fewer large cells and peak more strongly in the medium cell size range. Very few cells anywhere in the retina had areas larger than $500 \mu \mathrm{m}^{2}$. 

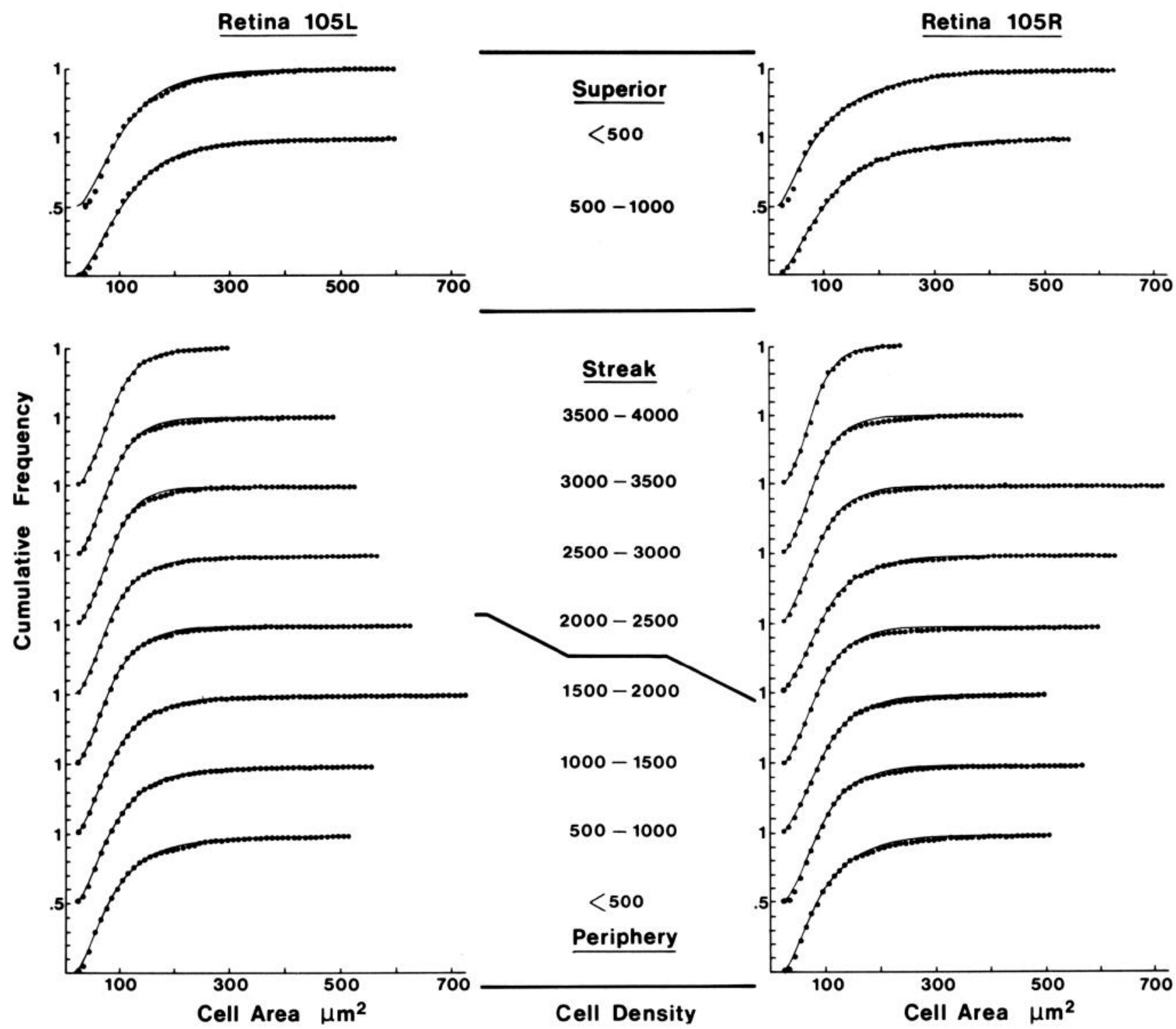

Figure 6. Cumulative cell area distributions as a function of cell density. These data points were generated by summing the successive frequencies in the corresponding histograms in Figure 5. Each data set spans a cumulative frequency range from 0.0 to 1.0 and the increments indicated on the ordinate are 0.1 unit. The smooth curves are Weibull functions which are described in the text. In this form, the data can be used to compare, among retinal regions, the proportions of cells falling in a given size range or, conversely, the size range encompassed by a specified proportion of the cell samples. For example, the median is that area for which the ordinate equals 0.5 . For the inferior retina, the medians differ by only a few square micrometers, while the median size in the superior retina is appreciably larger. Most of the difference in cell size distributions between retinal regions is occurring in the upper $50 \%$ of the cell size range.

sentation of large cells in the peripheral retina, both inferior and superior, is indicated by the more gradual rise of the functions and the long tails at large cell areas. This is particularly noticeable in the superior retina curves. At the same time, the differences between the inferior retina curves are not extreme, and the nature of the differences still remains to be considered.

As discussed under "Materials and Methods," we used Weibull functions to model the cumulative frequency distributions. The estimated parameters are given in Table I and the resulting Weibull functions are the smooth curves plotted through the data points in Figure 6 . The curves fit the data extremely well, except for the superior retina in which the analytical functions overestimate the number of very small cells. With this exception, we feel justified in using the family of Weibull functions as our basic description of ganglion cell size in the rabbit retina.

The appropriateness of this description is reinforced by returning to the smooth curves fit to the histograms in Figure 5 . These are the Weibull probability density functions obtained by differentiating the expression for $F(A)$ and incorporating the appropriate values for $\hat{\alpha}$ and $\hat{\beta}$. The coincidence with the cell size histograms in the inferior retina is remarkably good, especially since the curves were not specifically fit to the histograms. 
TABLE I

Characteristics of the Weibull functions

\begin{tabular}{|c|c|c|c|c|c|c|}
\hline \multirow{2}{*}{$\begin{array}{c}\text { Density } \\
\text { Region }\end{array}$} & \multicolumn{3}{|c|}{ Retina $105 \mathrm{~L}^{\alpha}$} & \multicolumn{3}{|c|}{ Retina $105 R^{b}$} \\
\hline & $\hat{\alpha}$ & $\hat{\beta}$ & $\begin{array}{c}\text { Median Cell } \\
\text { Area }\end{array}$ & $\hat{\alpha}$ & $\hat{\beta}$ & $\begin{array}{c}\text { Median Cell } \\
\text { Area }\end{array}$ \\
\hline & & & $\mu m^{2}$ & & & $\mu m^{2}$ \\
\hline \multicolumn{7}{|l|}{ Periphery } \\
\hline$<500$ & 1.871 & 2.964 & 78.6 & 1.932 & 3.303 & 84.8 \\
\hline $500-1000$ & 1.894 & 3.178 & 81.4 & 1.932 & 3.816 & 87.0 \\
\hline $1,000-1,500$ & 1.897 & 3.306 & 82.2 & 1.957 & 3.754 & 88.8 \\
\hline \multicolumn{7}{|l|}{ Visual streak } \\
\hline $2,000-2,500$ & 1.850 & 3.521 & 79.7 & 2.000 & 3.563 & 91.5 \\
\hline $2,500-3,000$ & 1.845 & 4.166 & 81.5 & 1.865 & 3.765 & 81.7 \\
\hline $3,000-3,500$ & 1.850 & 4.074 & 81.6 & 1.826 & 4.100 & 79.9 \\
\hline $3,500-4,000$ & 1.855 & 4.162 & 82.3 & 1.772 & 4.335 & 76.7 \\
\hline \multicolumn{7}{|l|}{ Superior retina } \\
\hline
\end{tabular}

${ }^{a}$ Regressions: $\hat{\alpha}=-0.00012 d+1.8871 ; r=-0.6587 . \hat{\beta}=0.0004 d+2.8701 ; r=0.9371$.

${ }^{b}$ Regressions: $\hat{\alpha}=-0.00004 d+1.985 ; r=-0.7194 . \hat{\beta}=0.0002 d+3.4227 ; r=0.7628$.

Although the changes occurring between cell size distributions in the inferior retina are small, it can be shown that the changes are both significant and systematic. This conclusion is embodied in the variation of the Weibull function parameters which are tabulated in Table I and plotted in the upper part of Figure 7. Since the parameter $\gamma$ was held constant, it has not been included.

The scaling parameter, $\hat{\alpha}$, exhibits very little change with ganglion cell density in the inferior retina. The regression line does have a slight negative slope, however, which is significantly different from zero $(\alpha<0.05)$. Small as the change may be, it is consistent between the two retinas. The shape parameter, $\hat{\beta}$, shows a definite increase with increasing cell density; the change is more pronounced in retina $105 \mathrm{~L}$ and the coefficient of correlation for the linear regression is also higher.

The small decrease in $\hat{\alpha}$ from the inferior periphery to the visual streak indicates a decrease in the large cell population and an increase in the proportion of small cells. The increase in $\hat{\beta}$, however, is indicative of decreases in both small and large cells and a corresponding increase in the medium cell population. Since both changes are occurring together and are to some extent offsetting, the expectation is that the large cell population will decline from the periphery to the visual streak. This supports the impression reached by inspection of the data in Figures 5 and 6 but adds an important additional conclusion: the change is linear with cell density. Having shown the significance and nature of the changes, the Weibull functions can be used to show more precisely their extent.

For each retina, we calculated the percentiles 10,25 , 50,75 , and 90 from the Weibull functions for the different density regions. These are shown in the lower graphs in Figure 7. The change in each percentile area with cell density indicates where the major changes in cell size are occurring. The three smallest percentiles for each retina $(10,25$, and 50$)$ show very little change from the inferior periphery to the visual streak, suggesting that the small and medium cell size populations are nearly constant throughout the inferior retina.

The most striking and consistent changes are those exhibited by the 75 th and 90 th percentiles. Both decrease from the periphery to the visual streak. Since the smaller percentiles do not change markedly, we may conclude that the variation in cell size distributions is a linear decrease in the large cell population from the inferior peripheral retina to the visual streak. Moreover, the decline in the 90th percentile is the more extreme, meaning that most of the decrease in large cells is within the largest $10 \%$ of the cell population.

Another way to evaluate the results is to select cell size groups and see what fraction each group contributes to the total cell population in each density region. Since the cell size distributions and their corresponding Weibull functions are unimodal, we have no basis on which to divide the samples into cell size groups. For purposes of comparison, however, we can use the cell size divisions used earlier by Hughes (1971). His diameter ranges of 6 to 10,10 to 14 , and 14 to $18 \mu \mathrm{m}$ correspond approximately to area divisions of 30 to 80,80 to 160 , and 160 to 260 $\mu \mathrm{m}^{2}$. We added a fourth category of cell areas larger than $260 \mu \mathrm{m}^{2}$ to include the full range of cell sizes that we observed.

As determined from the Weibull functions, the proportions of cells in these size ranges are shown in Figure 8 as a function of ganglion cell density. For the two largest cell size categories, the results are similar for both retinas; the proportions of cells between areas of 160 to 260 and $>260 \mu \mathrm{m}^{2}$ are declining from the inferior periphery to the visual streak. The retinas give different results for the two smallest cell size categories; it is the smallest cells which increase in retina $105 \mathrm{R}$, but the next largest category increases in retina $105 \mathrm{~L}$.

The failure of the data on the two retinas to agree completely is not altogether surprising. The retinas undoubtedly have been subject to different amounts of 

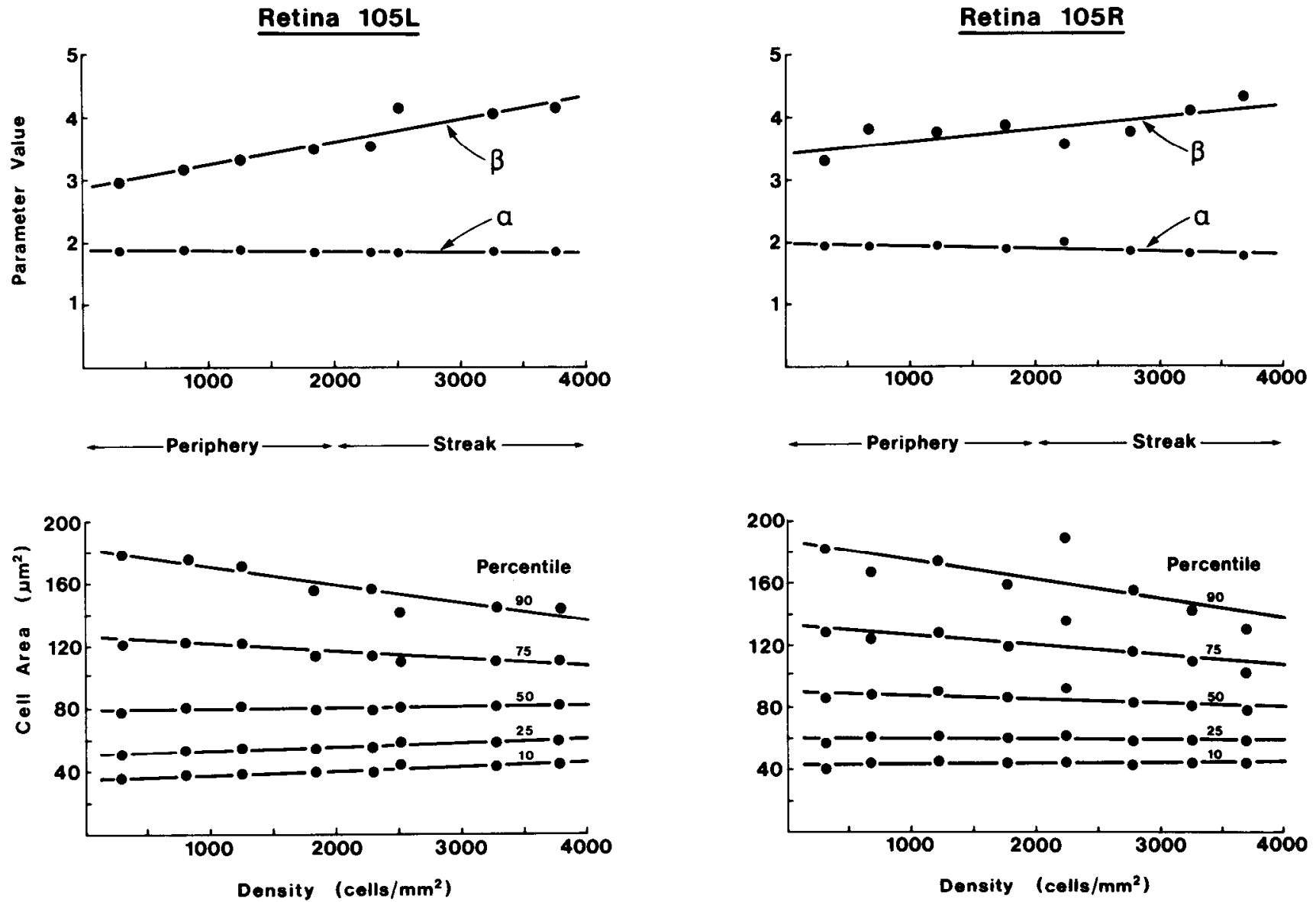

Figure 7. Parameters of the Weibull distributions (top) and percentile areas (bottom) as a function of cell density in the inferior retina. The two parameters which were allowed to vary in fitting Weibull functions to the data in Figure 5 are plotted in the upper graphs (the parameter $\gamma$ was constant at $15 \mu \mathrm{m}^{2}$ ). For both retinas, the shape parameter $\hat{\beta}$ increased and the scaling parameter $\hat{\alpha}$ decreased. The decrease in $\hat{\alpha}$, though small, was statistically significant. The equations for the regression lines are given in Table I. Area ranges encompassed by different percentiles of the distribution functions are given in the lower graphs. The smallest percentiles $(10,25$, and 50$)$ show little change in area with increasing cell density, indicating little change in the proportions of small cells between the periphery and the visual streak. The larger percentiles $(75$ and 90$)$ do decline, however, showing a decrease in the proportion of large cells from periphery to streak.

nonuniform shrinkage. The shrinkage effects should be more noticeable in comparisons of absolute cell size (Fig. 8) than in relative measures of cell size change (Fig. 7). In fact, the unknown influences of shrinkage argue against comparisons of absolute cell size ranges.

Regional variations unrelated to cell density. Since Provis (1979) concluded that the rabbit retina contains more very large ganglion cells near the temporal extremity of the visual streak, we looked for nasal-temporal differences in cell size distribution by several different methods. First, the retinal density maps were divided into nasal and temporal halves by a line passing vertically through the optic nerve head. The cell size histograms for nasal and temporal halves of the various isodensity regions were not significantly different. We also compared two retinal strips about $1 \mathrm{~mm}$ wide and $3 \mathrm{~mm}$ long (major axis vertical) located symmetrically at the ends of the visual streak, a comparison designed to replicate one made by Provis (see Figs. 9 and 11 of Provis, 1979). Again, no nasal-temporal difference in cell size distribution could be demonstrated. Finally, we located all of the cells in our samples with areas larger than $300 \mu \mathrm{m}^{2}$, corresponding roughly to the large cells ( $20 \mu \mathrm{m}$ diameter) mapped by Provis (1979). A temporal region of relatively high density for these cells was not found.

Although we could not confirm the presence of a nasaltemporal difference in cell size distribution in these retinas, we did find a clear difference between the superior and inferior retina (Figs. 5 and 6) which has not been reported before. The differences between the superior and inferior retina are reflected in the quantitative values of the Weibull distribution parameters; the $\hat{\alpha}$ values are particularly large for the superior retina samples (Table I) and are consistent with the presence of more large cells as noted earlier. It is also likely that an adequate fit of the Weibull functions to the superior retina data would require a larger value for $\gamma$, reflecting a relative scarcity of the smallest ganglion cells normally found in the inferior retina.

Unfortunately, we cannot comment on those portions of the superior retina having cell densities greater than 1,000 cells $/ \mathrm{mm}^{2}$. Density changes so rapidly on the superior aspect of the visual streak (Fig. 3) that our cell size samples taken at $1-\mathrm{mm}$ intervals include very few cells in this region.

The number of ganglion cells in the rabbit retina. We 
Retina 105L

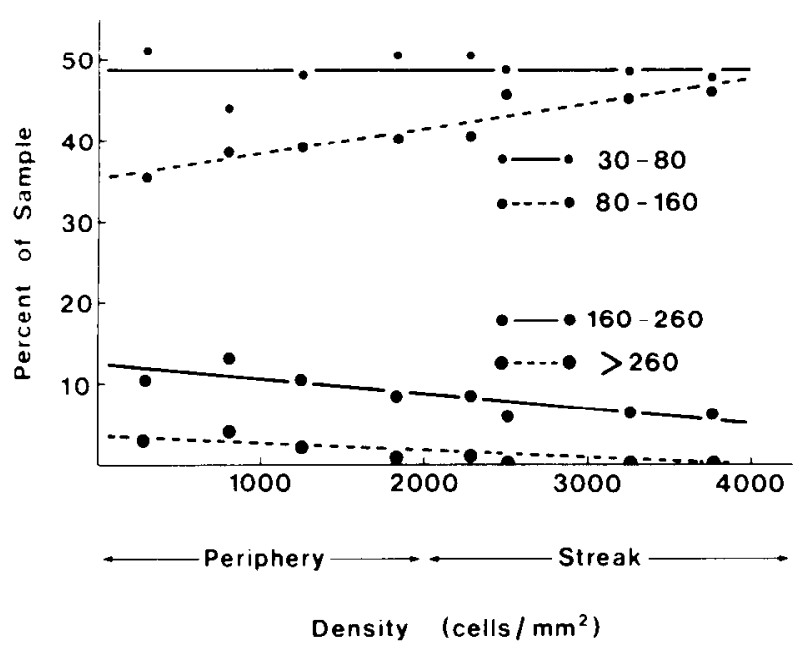

Retina 105R

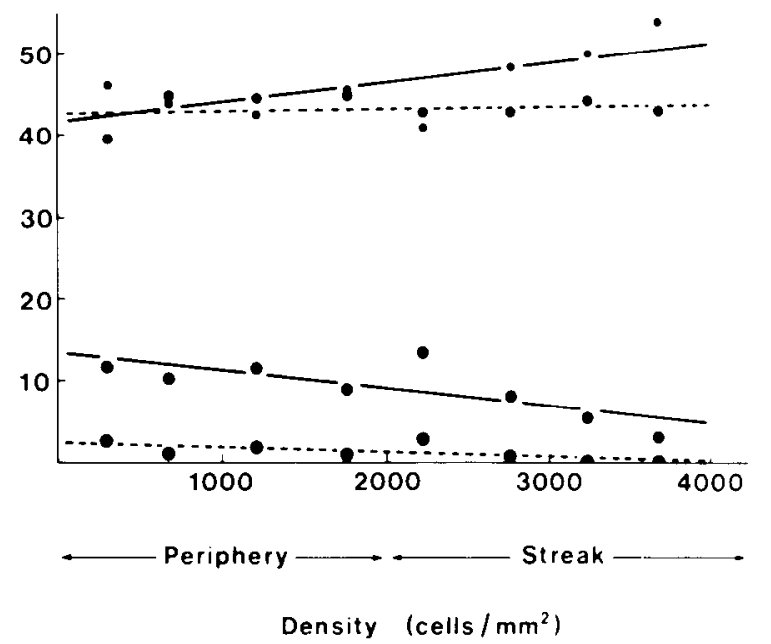

Figure 8. Proportions of cells in different size ranges as a function of cell density in the inferior retina. The data points were computed from the Weibull functions in Figure 6. Results for both retinas show that the proportions of large $\left(160\right.$ to $\left.260 \mu \mathrm{m}^{2}\right)$ and very large $\left(>260 \mu \mathrm{m}^{2}\right)$ cells decline from the periphery to the visual streak. The results for small $\left(30\right.$ to $\left.80 \mu \mathrm{m}^{2}\right)$ and medium $(80$ to $160 \mu \mathrm{m}^{2}$ ) cells differ for the two retinas. This difference may be attributable to differential shrinkage which has affected the visual streak region of retina $105 \mathrm{R}$ to a greater extent than in retina $105 \mathrm{~L}$.

have used cell density maps like those in Figure 4 to estimate the total number of ganglion cells in the rabbit retina. We began by measuring the areas bounded by isodensity contours at 500 cells $/ \mathrm{mm}^{2}$ intervals. These areas, multiplied by the mean number of cells per unit area, gave the estimated number of cells in a specific density region. The mean number of cells per unit area was determined by summing the individual densities from each count field in the particular region and dividing by the number of such count fields. Since the rate of change of cell density varies from one density region to the next, these mean densities are not exactly the same as the midpoint between the upper and lower isodensity limits. The area corresponding to the nerve head was not included in the total retinal area. The results of these calculations are shown in Table II.

The estimated number of cells in each density region obviously varies between retinas, but the difference between the highest and lowest estimates is no greater than $15 \%$ for any region. When the number of cells in a given density region is converted to a percentage of the total, the consistency between the three retinas is even more striking. Except for the high density regions in retina $103 \mathrm{R}$, the proportion of cells in a given density region varies only a few percent between retinas. Our mean estimate of 406,375 ganglion cells in the rabbit retina is within the figure of 374,000 to 414,000 optic nerve fibers established by Vaney and Hughes (1976).

In these three retinas, the visual streak occupied between $9.5 \%$ and $10.7 \%$ of the total retinal area (mean $=$ $9.9 \%$ ). The number of ganglion cells in this region was between $34.0 \%$ and $37.1 \%$ of the total number of cells (mean $=35.1 \%)$. In other words, the visual streak, which comprises about one-tenth of the total retina, contains just over one-third of the ganglion cells.

Other estimates of the number of ganglion cells are 547,000 (Vaney and Hughes, 1976), 262,000 (Provis, 1979), and 373,500 (Vaney, 1980). Since these ganglion cell counts used computation methods similar to ours, the discrepancies should be explained. The simplest explanation of the low number obtained by Provis (1979) is that many cells were excluded from the counts, and they should not have been. Although the proportion of excluded cells was not specified, it appears to have been a substantial fraction of the total. The count by Vaney and Hughes (1976) was later thought to have included ganglion cells, coronate cells, and some "unclassified" cells. Vaney's (1980) recent estimate of 373,500 cells removed the coronate and unclassified cells from the original count.

Relative to the optic nerve axon count, Vaney's (1980) ganglion cell estimate is a bit low and ours is somewhat high. Even so, the estimates differ by only $8 \%$ and this agreement is certainly acceptable given the assumptions and corrections involved.

\section{Discussion}

Ganglion cells, glia, or displaced amacrine cells? The cell counts and cell area measurements in this study were subject to two sources of ambiguity. The first was the presence of glial cells in the ganglion cell layer. Features of size, shape, and staining properties of glial cells have been discussed by a number of other workers (e.g., Hughes, 1975; Stone, 1978; Vaney, 1980) and these criteria permit glia to be removed from the sample with a fair degree of confidence. Errors introduced by confusing glia and small ganglion cells were probably inconsequential.

A more serious question concerns the identity of those cells which remain after the obvious glia have been eliminated; a substantial portion of them are probably displaced amacrine cells. The rabbit retina contains cholinergic amacrine cells (Masland and Mills, 1979); many are displaced and may constitute up to $20 \%$ of the cells in the ganglion cell layer (Hayden et al., 1980). Displaced amacrine cells also have been demonstrated by their 
TABLE II

Estimates of total ganglion cell number ${ }^{a}$

\begin{tabular}{|c|c|c|c|c|c|c|c|c|c|c|c|c|c|c|c|}
\hline \multirow{3}{*}{$\begin{array}{l}\text { Density } \\
\text { Region }\end{array}$} & \multicolumn{5}{|c|}{ Retina $105 \mathrm{~L}$} & \multicolumn{5}{|c|}{ Retina 105R } & \multicolumn{5}{|c|}{ Retina 103R } \\
\hline & \multicolumn{2}{|c|}{ Area } & \multirow{2}{*}{$\begin{array}{l}\text { Mean } \\
\text { Den- } \\
\text { sity }\end{array}$} & \multicolumn{2}{|c|}{ Number of Cells } & \multicolumn{2}{|c|}{ Area } & \multirow{2}{*}{$\begin{array}{l}\text { Mean } \\
\text { Den- } \\
\text { sity }\end{array}$} & \multicolumn{2}{|c|}{ Number of Cells } & \multicolumn{2}{|c|}{ Area } & \multirow{2}{*}{$\begin{array}{c}\text { Mean } \\
\text { Den- } \\
\text { sity }\end{array}$} & \multicolumn{2}{|c|}{ Number of Cells } \\
\hline & $\mathrm{mm}^{2}$ & 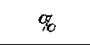 & & No. & $\%$ & $\mathrm{~mm}^{2}$ & $\mathscr{B}$ & & No. & $\%$ & $\mathrm{~mm}^{2}$ & $\mathscr{B}$ & & No. & 9 \\
\hline $500-1,000$ & 114.8 & (25.7) & 804 & 92,289 & (23.5) & 132.0 & $(25.1)$ & 675 & 89,100 & (21.9) & 132.5 & $(25.4)$ & 624 & 82,680 & (19.7) \\
\hline $1,000-1,500$ & 46.5 & (10.4) & 1,252 & 58,218 & (14.8) & 43.3 & $(8.2)$ & 1,210 & 52,393 & $(12.9)$ & 59.4 & (11.4) & 1,228 & 72,943 & (17.4) \\
\hline $1,500-2,000$ & 24.7 & $(5.5)$ & 1,834 & 45,300 & $(11.6)$ & 23.0 & (4.4) & 1,767 & 40,641 & $(10.0)$ & 23.9 & $(4.6)$ & 1,761 & 42,088 & $(10.0)$ \\
\hline $3,000-3,500$ & 13.0 & (2.9) & 3,266 & 42,458 & $(10.8)$ & 14.3 & $(2.7)$ & 3,242 & 46,361 & (11.4) & 7.1 & (1.4) & 3,198 & 22,706 & (5.4) \\
\hline $3,500-4,000$ & 4.9 & (1.1) & 3,761 & 18,429 & $(4.7)$ & 2.9 & $(0.5)$ & 3,670 & 10,643 & (2.6) & 5.4 & $(1.0)$ & 3,704 & 20,002 & (4.8) \\
\hline $4,000-4,500$ & 0.7 & $(0.2)$ & 4,209 & 2,940 & $(0.8)$ & 0.1 & $(<0.1)$ & 4,014 & 401 & $(0.1)$ & 7.6 & $(1.5)$ & 4,212 & 32,011 & (7.6) \\
\hline $4,500-5,000$ & 0.1 & $(<0.1)$ & 4,842 & 484 & $(0.1)$ & & & & & & 3.2 & $(0.6)$ & 4,657 & 14,902 & (3.6) \\
\hline $5,000-5,500$ & & & & & & & & & & & 0.6 & $(<0.1)$ & 5,155 & 3,093 & $(0.7)$ \\
\hline $\begin{array}{l}\text { Periphery } \\
(<2,000)\end{array}$ & 398.6 & $(89.3)$ & & 259,938 & $(66.0)$ & 475.5 & $(90.4)$ & & 267,512 & $(65.7)$ & 471.5 & $(90.5)$ & & 263,937 & (62.9) \\
\hline Totals & 446.6 & & & 392,346 & & 526.0 & & & 407,175 & & 520.9 & & & 419,603 & \\
\hline
\end{tabular}

a The mean area was $497.8 \mathrm{~mm}^{2}$ and the mean number of ganglion cells was 406,375 .

immunoreactivity to substance $\mathrm{P}$ (Famiglietti et al., 1980) and by staining with intraretinal injections of horseradish peroxidase (Amthor et al., 1980). It also has been argued that a particular group of cells in the ganglion cell layer, the coronate cells, can be distinguished in Nissl-stained preparations and that these are also displaced amacrine cells (Hughes and Vaney, 1980; Vaney et al., 1981). The proportion of coronate cells ranges from approximately $7 \%$ in the visual streak to some $30 \%$ in the peripheral retina.

It is clear from the results with horseradish peroxidase staining that small ganglion cells and displaced amacrine cells can have the same soma diameters. They differ, however, in the way dendrites branch from the soma. Displaced amacrine cells tend to have just a few primary dendrites which branch toward the inner plexiform layer, leaving the soma's cross-sectional outline quite smooth in appearance. Ganglion cells not only have more dendrites but they generally branch more laterally. Since the Nissl stains encroach a bit into the initial segment of the primary dendrites, the ganglion cell somata have a characteristic irregular outline (see, for example, Figs. 1 and 2).

Our criterion for identifying ganglion cells is based largely on soma shape. It is fairly simple to apply and produces consistent results. Like other criteria for distinguishing ganglion cells from other cells in Nissl-stained preparations, however, there is no unequivocal independent check on the validity of the criterion used. Even so, there are several reasons for believing that we have, for the most part, excluded displaced amacrine cells from our sample. First, judged by the photographs of glia, ganglion cells, and coronate cells presented by Hughes and Vaney (1980), the coronate cells have smooth, continuous outlines, which fits with our criterion. Second, our cell size histograms (Fig. 5) do not show many more small cells in the peripheral retina; the presence of coronate cells should be most obvious here (Hughes and
Vaney, 1980; Vaney et al., 1981). Finally, our estimates of the total number of ganglion cells in the rabbit retina agree well with Vaney and Hughes' (1976) count of optic nerve axons. This suggests that, if coronate cells or displaced amacrine cells were included in our ganglion cell samples, their proportion was quite small.

Nature of the visual streak. As Hughes (1977) has pointed out, the rabbit's visual streak is different from that in most other retinas; there is no single localized region of high cell density. Instead, as we have shown in Figure 3, the peak cell density is fairly uniform along a ridge extending horizontally across the retina.

By convention, the boundary of the visual streak is taken to be the 2,000 cells $/ \mathrm{mm}^{2}$ isodensity contour (Hughes, 1971). It should be noted, however, that there is no sharp demarcation between the streak and the peripheral retina. A slightly less arbitrary criterion for the visual streak limit would be the cell density at which the rate of density change shows a marked inflection between slowly increasing density in the peripheral retina and rapidly increasing central density. Figure 3 suggests that this inflection, in the inferior retina, occurs at about 1,500 cells $/ \mathrm{mm}^{2}$.

In a sense, the smooth, continuous variations of cell density and cell size from the inferior peripheral retina to the central retina conflict with electrophysiological results showing different distributions of physiological cell classes in these two regions (Levick, 1967; Oyster, 1968). This apparent dichotomy was inevitable, however, since the physiological studies pooled the cell samples from these two retinal regions. A more likely situation is one of continuous change in the proportions of physiological cell classes. Thus, the various cell groups would be represented differently in the center of the visual streak and the extreme inferior periphery but would have nearly similar proportions on either side of the visual streak boundary.

In other words, our results suggest that the visual 
streak is not fundamentally different from the rest of the inferior retina. Since it represents one extreme of a continuum of variable properties, however, the visual streak still must be regarded as a special region of particular functional importance.

Cell size and retinal location. There are several major differences between our conclusions and those of earlier studies of rabbit retinal ganglion cell size. First, we found that ganglion cell soma size does not change markedly, within the inferior retina, between the periphery and the visual streak (Figs. 5 and 6). Even though the changes are small, they are quite systematic. We described the cell size distributions with Weibull functions and found that only one of the three functional parameters changed markedly with ganglion cell density (Fig. 7). This estimated parameter, $\beta$, increased linearly as a function of cell density; from the inferior periphery to the visual streak, it characterizes a decline in proportions of large and very large cells and a slight increase in the proportion of small to medium cells (Fig. 7). A slight decline in the other variable parameter, $\hat{\alpha}$, acts to prevent much change in the small cell population.

The decreasing proportion of large cells from the periphery to the visual streak agrees with earlier results, but we found the changes to be very much smaller than Hughes (1971) reported. We did not find, however, either a substantial increase in the small cell population or a sharp decrease in the medium cell group in the visual streak (Hughes, 1971). The changes that we observed were quite small and in the opposite directions (Figs. 7 and 8).

Our results also differ from the ganglion cell diameter histograms presented by Vaney (1980). I Iis histograms show a definite increase in the proportion of small cells from the inferior periphery to the visual streak, although the increase appears smaller than in the earlier results by Hughes (1971). In this case, however, the histograms excluded a group of small "unclassified" cells which were thought to be neither glia nor coronate cells. We have undoubtedly called these ganglion cells and their presence, particularly in our peripheral retina samples, would explain much of the difference between Vaney's histograms and ours. Although these unclassified cells have been treated as something other than ganglion cells (Hughes and Vaney, 1980), the evidence (lack of horseradish peroxidase back-filling) is not compelling.

In another recent study, cells in the ganglion cell layer of rabbit retina were divided into three groups: glia, displaced amacrine cells, and ganglion cells (Vaney et al., 1981). The ganglion cell soma size histograms for the mid and far peripheral inferior retina, where the proportion of displaced amacrine cells is thought to be highest, peaked at values considerably larger than those shown in Figure 5. If the displaced amacrine and ganglion cells were to be combined, however, the resulting histograms would be much more like those presented here.

Since the neurofibrillar stains used by Vaney et al. (1981) to identify displaced amacrine cells also stain some ganglion cells, it is possible that a portion of the cells designated as displaced amacrine cells are small ganglion cells whose fine axons are resistant to the reduced silver stains. If so, much of the difference between their gan- glion cell size histograms and our results could be explained on this basis.

Another major difference is that we have been unable to confirm the report by Provis (1979) that very large ganglion cells ( $>20 \mu \mathrm{m}$ diameter or $300 \mu \mathrm{m}^{2}$ area) have a peak density near the temporal end of the visual streak. In general, we found the density of these very large cells to be nearly constant throughout the inferior retina, including much of the visual streak. We have no certain explanation for the discrepancy between our results and those by Provis except to comment that the methods for locating large cells were different. We measured areas, whereas Provis located large cells by eye, i.e., subjectively. Since there is no discontinuity in the cell size histograms to separate large cells from smaller cells, the subjective evaluation has more potential for error. On the other hand, we measured cell areas at 1-mm intervals; it is possible that we missed the large cell area in both retinas, although Provis's maps showed it to be several millimeters in extent.

Finally, we found the cell size distributions in the superior retina to be clearly different from those in comparable regions of the inferior retina (Figs. 5 and 6 ; Table I). At present, we do not know what this difference means; we have no reason to suspect a similar shrinkage artifact in both retinas. If we assume that different soma size ranges may be associated with different physiological cell groups, it is possible that the superior retina has physiological classes of ganglion cells in different proportions than the inferior retina or that new physiological cell classes may be found here. Preliminary results from ganglion cell recordings in the superior retina support the former hypothesis (M. -S. Lee, E. S. Takahashi, and C. W. Oyster, unpublished observations).

Soma size and cell classification. In studying ganglion cell size in rabbit retina, one possibility was that limited ranges of soma sizes might be associated with specific morphological or physiological cell classes. It is clear, however, that the soma size histograms do not exhibit more than one statistically significant mode; thus, the soma size results are mute with respect to this problem.

It is possible that a given physiological or morphological cell group contains all soma sizes. On the other hand, we have evidence that at least one class, the on-type direction-selective cells, have somata which are among the largest in the ganglion cell population (Oyster et al., 1980). It might seem that the lack of a secondary mode representing the on-type direction-selective cells in the overall cell size distribution is contradictory, but there are some good reasons why a subsidiary size mode for this or any other discrete cell class should not be present.

In the particular case of the on-type direction-selective cells, this group constitutes only 5 to $7 \%$ of the total ganglion cell population (based on extracellular recording frequency) but have somata which are spread throughout the largest $20 \%$ of the cell population. There must be other cell types whose somata fall in the same range of sizes, probably with somewhat different distributions. Thus, the contribution of the on-type direction-selective cells to the overall distribution of soma size is small, on the one hand, and intermingled with cells from different groups, on the other. Viewed in this light, the multitude 
of physiological cell types in the rabbit retina makes it unlikely that any one group can make a distinguishable contribution to the overall cell size histograms.

To be sure, ganglion cell size histograms with several modes have been reported, those for cat retina being the most clear cut and most extensively documented. The $\alpha$ cell group has soma diameters which are completely separate from the rest of the cell size distribution (Boycott and Wässle, 1974). It should be recognized, however, that this is an exceptional case, and the cat retina is not representative of other species in which ganglion cell size has been studied. In other retinas, subsidiary modes are small and none show the separation of a cell population in any way comparable to the $\alpha$ cells in cat retina.

Analytical description of cell size. The Weibull functions that we have used to characterize the ganglion cell size distributions in rabbit retina are potentially applicable to a variety of similar problems in retina and central brain nuclei. As an example, soma size distributions of cat lateral geniculate neurons (Hickey et al., 1977) have been treated successfully with Weibull functions (Kirk, 1976). The wide variations in shape obtainable with the Weibull functions lead us to believe that other cell size distributions will be readily described by this family of curves.

In addition to the advantages of data smoothing, quantitative description, and statistical evaluation, the modeling of cell size distributions with Weibull or other analytical functions provides a very concise description of cell size change. In this particular case, ganglion cell size in the rabbit's inferior retina can be described by the equation

$$
F(A)=1-\exp -[(\ln A / 15) / 1.86]^{\beta}
$$

Using mean values of $\hat{\alpha}$ and $\hat{\beta}$ from two retinas, $\alpha=1.86, \gamma=15$, and $\beta=0.0003$ (density) +3.19 . Thus, for a particular ganglion cell density, the distribution function of ganglion cell area can be obtained by solving for $\beta$ and then using this value to solve for $F(A)$ at different cell areas. The derivative of the distribution function gives the corresponding probability density function. Similar descriptive equations for other retinas would provide a more rigorous method of interspecies comparison. The same approach also would apply to problems of evaluating cell size changes in retina or central nuclei as a function of time during periods of cell growth.

The analytical method using Weibull functions might not appear to apply to multimodal cell size histograms like those in cat retina. We are not aware of any $a$ priori reason, however, why these distributions could not be characterized by the appropriate combination of several Weibull functions. Such a description certainly would provide a marked improvement in our ability to state how cell sizes within specific groups change as a function of retinal eccentricity and may solve statistical analysis problems encountered in evaluating ganglion cell size in cat retina (e.g., Stone et al., 1978).

It is also possible that the Weibull functions may prove useful in the description and evaluation of neuronal features other than soma size. Axon diameter distributions, for example, are characteristically skewed (e.g.,
Vaney, 1980) and would be obvious candidates for this approach. Other morphological characteristics involving size, such as dendritic branch angles or dendritic lengths, also may follow this particular distribution (cf., Lindsay and Scheibel, 1976). The ability of the analysis to characterize skewed distributions and, as we have shown, to detect relatively small changes between distributions makes the method worth serious consideration for problems of this type.

\section{References}

Amthor, F. R., C. W. Oyster, and E. S. Takahashi (1980) Morphological classification of rabbit retinal ganglion cells. Soc. Neurosci. Abstr. 6: 213.

Barlow, H. B., R. M. Hill, and W. R. Levick (1964) Retinal ganglion cells responding selectively to direction and speed of image motion in the rabbit. J. Physiol. (Lond.) 173: 377407.

Bech, K. (1957) The basophilic substances in the retinal ganglion cells and the physiological activity changes in these cells. Acta Ophthalmol. (Suppl.) (Copenh.) 46: 1-105.

Boycott, B. B., and H. Wässle (1974) The morphological types of ganglion cells of the domestic cat's retina. J. Physiol. (Lond.) 240: 397-419.

Caldwell, J. H., and N. W. Daw (1978) New properties of rabbit retinal ganglion cells. J. Physiol. (Lond.) 276: 257-276.

Davis, F. A. (1929) The anatomy and histology of the eye and orbit of the rabbit. Trans. Am. Ophthalmol. Soc. 27: 401-441.

Famiglietti, E. V., N. C. Brecha, and H. J. Karten (1980) Neural localization of substance P-like immunoreactivity in rabbit retina. Soc. Neurosci. Abstr. 6: 212.

Freeman, B., and E. Tancred (1978) The number and distribution of ganglion cells in the retina of the brush-tailed possum, Trichosurus vulpecula. J. Comp. Neurol. 177: 557-568.

Fukuda, Y. (1977) A three-group classification of rat retinal ganglion cells. Histological and physiological studies. Brain Res. 119: 327-344.

Hayden, S. A., J. W. Mills, and R. H. Masland (1980) Acetylcholine synthesis by displaced amacrine cells. Science 210: 435-437.

Hebel, R. (1976) Distribution of retinal ganglion cells in five mammalian species (pig, sheep, ox, horse, dog). Anat. Embryol. (Berl.) 150: 45-51.

Hebel, R., and H. Hollander (1979) Size and distribution of ganglion cells in the bovine retina. Vision Res. 19: 667-674.

Hickey, T. L., P. D. Spear, and K. E. Kratz (1977) Quantitative studies of cell size in the cat's dorsal lateral geniculate nucleus following visual deprivation. J. Comp. Neurol. 172: 265-282.

Hokoc, J. N., and E. Oswaldo-Cruz (1979) A regional specialization in the opossum's retina: Quantitative analysis of the ganglion cell layer. J. Comp. Neurol. 183: 385-396.

Hughes, A. (1971) Topographical relationships between the anatomy and physiology of the rabbit visual system. Doc. Ophthalmol. 30: 34-159.

Hughes, A. (1972) A schematic eye for the rabbit. Vision Res. 12: $123-138$.

Hughes, A. (1975) A quantitative analysis of the cat retinal ganglion cell topography. J. Comp. Neurol. 163: 107-128.

Hughes, A. (1977) The topography of vision in mammals of contrasting life style: Comparative optics and retinal organization. In Handbook of Sensory Physiology: The Visual System in Vertebrates, Vol. VII/5, F. Crescitelli, ed., pp. 613756, Springer-Verlag, Berlin.

Hughes, A., and D. I. Vaney (1980) Coronate cells: Displaced amacrines of the rabbit retina? J. Comp. Neurol. 189: 169189.

Johnson, N. L., and S. Kotz (1970) Continuous Univariate 
Distributions-1, Houghton Mifflin Co., Boston.

Kirk, K. A. (1976) An investigation of a family of size distributions. Doctoral dissertation, University of Alabama in Birmingham.

Levick, W. R. (1967) Receptive fields and trigger features of ganglion cells in the visual streak of the rabbits' retina. J. Physiol. (Lond.) 188: 285-307.

Lindsay, R. D., and A. B. Scheibel (1976) Quantitative analysis of dendritic branching pattern of granular cells from human dentate gyrus. Exp. Neurol. 52: 295-310.

Marquardt, D. W. (1963) An algorithm for least-squares estimation of non-linear parameters. J. Soc. Ind. Appl. Math. 11: 431-441.

Masland, R. H., and J. W. Mills (1979) Autoradiographic identification of acetylcholine in the rabbit retina. J. Cell Biol. 83: 159-178.

Oyster, C. W. (1968) The analysis of image motion by the rabbit retina. J. Physiol. (Lond.) 199: 613-635.

Oyster, C. W., J. I. Simpson, E. S. Takahashi, and R. E. Soodak (1980) Retinal ganglion cells projecting to the rabbit accessory optic system. J. Comp. Neurol. 190: 49-61.

Provis, J. M. (1979) The distribution and size of ganglion cells in the retina of the pigmented rabbit: A quantitative analysis. J. Comp. Neurol. 185: 121-138.
Siegel, S. (1956) Nonparametric Statistics for the Behavioral Sciences, McGraw-Hill, New York.

Stone, J. (1978) The number and distribution of ganglion cells in the cat's retina. J. Comp. Neurol. 180: 753-772.

Stone, J., M. H. Rowe, and J. E. Campion (1978) Retinal abnormalities in the Siamese cat. J. Comp. Neurol. 180: 773782.

Tiao, Y. -C., and C. Blakemore (1976) Regional specialization in the golden hamster's retina. J. Comp. Neurol. 168: 439458.

Vaney, D. I. (1980) A quantitative comparison between the ganglion cell populations and axonal outflows of the visual streak and periphery of the rabbit retina. J. Comp. Neurol. 189: 215-233.

Vaney, D. I., and A. Hughes (1976) The rabbit optic nerve: Fibre diameter spectrum, fibre count, and comparison with a retinal ganglion cell count. J. Comp. Neurol. 170: 241-252.

Vaney, D. I., L. Peichl, and B. B. Boycott (1981) Matching populations of amacrine cells in the inner nuclear and ganglion cell layers of the rabbit retina. J. Comp. Neurol. 199: 373-391.

Wässle, H., W. R. Levick, and B. G. Cleland (1975) The distribution of the alpha type of ganglion cells in the cat's retina. J. Comp. Neurol. 159: 419-438. 